\title{
Teachers' Perceptions about the Barriers and Catalysts for Effective Practices with ICT in Primary Schools
}

\author{
Eva Dakich \\ Victoria University, Australia \\ eva.dakich@vu.edu.au
}

\begin{abstract}
This paper presents perceptions of four primary school teachers from two Victorian government primary schools about the barriers and catalyst for effective practices with ICT. Findings of the semi-structured qualitative interviews confirm results of previous studies indicating that access to reliable infrastructure, adequate technical support, and time pressures are still considered to be some of the most significant barriers to successful ICT integration in public schools. Teacher interviews however also reveal that the challenges of integrating ICT in teaching and learning can be counterbalanced by a number of variables, which include: owning a laptop, having access to ongoing professional learning, sharing effective practices, drawing on student expertise and being supported by a whole-school approach to teaching and learning with ICT.
\end{abstract}

Keywords: Teachers, primary schools, ICT integration, barriers, catalysts.

\section{Introduction}

Information and Communication Technologies (ICT) have been introduced to schools, yet without fundamentally changing teaching and learning. In most cases they have been adapted to traditional school structures, classroom organisation and existing teaching practices, falling short of facilitating significant educational change and reform $[1,2]$. The slow uptake of new technologies has been associated with a combination of the following factors: limited access to ICT infrastructure, lack of technical support, lack of time, insufficient support from school leadership including limited opportunities for on-going professional development [3-5].

Findings of recent research studies reveal that access to current and reliable ICT infrastructure still seems to be one of the major barriers to technology use in schools. For example the results of the 2005 PISA evaluation showed that according to school principals participating in this large scale international study, shortage or inadequacy of hardware and software hinders schools in taking advantage of the promises of ICT [6]. However there are studies [3, 4, 7] that illustrate that even in well-resourced schools, ICT integration lags behind expectations. By observing, interviewing and surveying teachers, students and school staff of two high schools located in Silicon Valley Cuban et al. [4] found that access to ICT does not always guarantee its widespread use in the classroom, and that teachers typically use new technologies to sustain rather than transform their teaching practices. Findings of this study indicated that teachers did not have sufficient time to experiment with new technologies; available 
training was not specific to their needs and was not offered at convenient times. The authors also emphasised the importance of organisational context and the cultural/historical aspects of teaching and schooling over individual teacher characteristics, such as age and gender.

In a mixed methods study of thirty 'tech-savvy' teachers from technology rich elementary, middle and high schools in the United States, Bauer and Kenton [3] revealed that true integration of computer technologies (CT) did not happen, and that even technologically skilled and innovative teachers did not integrate CT consistently into their practices as a "teaching and learning tool" (p. 519). Similarly to Cuban et al.'s [4] findings, one of the key obstacles appeared to be time, along with outdated hardware, lack of software, and discrepancies in student skill level. The authors asserted that the real issue for schools was not so much the number of computers available to students but how they were being used by the teachers. As the evidence from empirical studies demonstrates, digital divide goes beyond "simple binaries of technology haves and have nots" [8, p. 42]. It includes new forms of divide such as mastery and pedagogical understanding of new technologies, and access to relevant and new learning experiences through and with ICT $[9,8,10,11]$.

Wood, Mueller, Willoughby, Specht and Deyoung [12] also emphasised the pivotal role of teachers in successful technology integration. They asserted that most research aiming to understand the barriers to effective integration of ICT drew their conclusions from survey data and occasional observational work. In their opinion such studies do not provide a "context-rich consideration of how these variables are perceived by teachers, and how teachers believe that these variables impact on practice" (p.184). Wood et al. [12] found it critical to allow teachers to reflect and elaborate from their own perspective on what could be the barriers to successful technology integration.

To respond to the gap in contemporary research identified by Wood et al. [12], this paper provides an insight into teachers' perceptions about the barriers and catalysts for effective practices with ICT.

\section{Method}

Semi-structured qualitative interviews [13] were conducted with four teachers from two Victorian government primary schools located in the western metropolitan suburbs of Melbourne. The interviews were an integral part of a qualitative fieldwork in a mixed methods research project that explored connections between teachers' ICT literacy and pedagogical practices [14]. Participating teachers were selected by purposeful sampling $[15,16]$, based on professional engagement and innovative practices. Data was collected in 2005. Interviews were audio recorded, and interview transcripts were analyzed by methods of qualitative data analysis $[17,18]$. In order to protect the anonymity and safeguard confidentiality, pseudonyms were used [19] when referring to teachers or schools participating in this research.

To ensure the validity [16] or trustworthiness [20, 21] of the findings and interpretations emerging from the teacher interviews, Creswell and Miller's [22] twodimensional model was utilised. This included triangulation and audit trail or peer review. Findings were triangulated by using multiple sites for data collection, and by using multiple sources and sets of data emerging from the mixed methods project. An 
audit trail, consisting of peer-review and debriefing by the supervisors of this $\mathrm{PhD}$ project, was also used to strengthen the validity of interpretations. While recommended by Creswell and Miller [22], member-checking was not performed, as Boden and Walsh's [23] and Harris' [24] position on this matter was adopted. According to Harris [24] member-checking produces "a new set of data, unable to confirm the original set even though they are likely to be similar" [24, p. 61], and may alter the original findings. However, by some, this could be perceived as a limitation of the study reported on in this paper.

\section{Teaching and Learning with ICT}

Teachers participating in the interviews (Maria, Kate, Gina and Joanne) demonstrated an acute awareness of the importance of facilitating student learning with ICT. They believed that socialising students into the digital world was one of their responsibilities. Demonstrating a pragmatic viewpoint, teachers thought that empowering students with ICT skills provides them with "skills for work and life" (Gina), which translates into more opportunities for future employment and a better position in the society. Apart from being aware of the social responsibility that comes with the integration of ICT, teachers also realised the pedagogical potential of ICT and perceived it as a "new tool for changing education" (Gina), which offers students more resources and opens up new opportunities for learning. ICT was also viewed as a component of multiliteracies, "a medium for providing students with a range of experiences" (Joanne), and a "powerful instrument for canvassing their learning" (Gina).

\subsection{Barriers to Effective ICT Integration}

Despite teachers' enthusiasm and genuine intention to provide students with the best opportunities for learning, the effective integration of ICT in learning and teaching encounters many obstacles. Findings of the teacher interviews suggest that some of the major barriers to effective ICT integration are access to software and hardware, unstable networks, issues related to time, and limited technical support.

Kate and Maria are team-teaching grade 3 and 4 students at Kookaburra primary school. In their opinion limited access and technical difficulties prove to be major barriers to successful technology integration: "We have got four computers per classroom. This is in our room, so we've got basically four computers to accommodate 26 students" (Kate). To ensure equitable access Kate and Maria created a timetable to provide all students with equal opportunities of having hands-on experiences with technology. Although this seems to be working well, Maria believes that having more computers would make a real difference:

...to be successful, you need every child to have a computer, just like teachers do now. They all have their own laptop, and teachers are using it and learning about it. The only way is hands on. (Maria)

Technical difficulties often trigger feelings of helplessness and anxiety. Some of the most common technical problems appear to be those linked to unreliable networks. As Maria puts it: “...the problem there which we mainly and always come 
across is if the network's down ... and I'm thinking: Oh, my God what do we do now?"

At Kookaburra Primary School there is no just-in-time technical support available to assist teachers and students with such glitches. The technician comes in two days per week. Teachers have to register their ICT-related problems into a logbook:

....it may take two weeks [for the problem to be solved] - and two weeks is a lot of time wasting for the children. They miss out on opportunities and not knowing so much about computers the both of us, it makes it more difficult ... getting them [computers] working ... You can't pull out another teacher from another grade, 'cause it's wasting their teaching time, so it makes it more difficult. That's a big problem that we have. (Maria)

Gina and Joanne teach grade 5 and 6 students at Platypus Primary School, where in their opinion there are no significant issues with access to new technologies. However, similarly to their colleagues from Kookaburra Primary School, technical glitches and unstable networks often hinder their practices with ICT. According to Joanne such difficulties can be frustrating at times so learning to cope with them is an imperative.

Apart from difficulties related to unstable networks, time and traditional timetables interfere with opportunities for new learning. In Gina's opinion effective practices with ICT are restricted by existing timetables which do not allow time for exploration, research and collaboration:

What happens with research - you'd like a bit more time. Once you start getting into it, you'd like to not stop and start. But because of the timetable session of an hour, the children are restrained by time. Say, it was back in the classroom, and the computers could be used quite independently, the students could come and go as needed. (Gina)

\subsection{Catalysts for Pedagogical and Cultural Shifts}

Teacher interviews also reveal that there are a number of variables that help minimise the challenges and risks related to integration of ICT and contribute to pedagogical and cultural shifts. Teachers argue that having their own computer and having time to practice their skills help them build competence and confidence in using new technologies. They also believe that professional learning opportunities, collaboration and supportive school culture contribute to effective and innovative practices with ICT.

One of the initiatives that has made a real difference to teachers' use of computers has been the Notebooks for Teachers and Principals Programme, initiated by the Victorian Department of Education and Training [25] in 1998. Since then the Victorian Government has been providing school teachers and principals in Victorian government schools with laptops on a three-year lease period. The results of this initiative speak for themselves. Teachers argue that laptops helped them become more familiar with ICT, and provided them with opportunities to experiment with new technologies in their own time and within their own comfort zone. 
Before, I knew nothing with these computers. Since having it at home, and having the time (because you never have time at school), I've just learnt so much, and I'm very proud of myself, of what I have learnt, because I was very, very computer illiterate. I was a one-finger, where's-the-A, where's-the-B. (Maria)

Maria says that having a laptop is very different from having access to a desktop computer at school. Laptops provide flexibility in time and space and convenience, since teachers have no time at school to experiment with technology.

Access to relevant professional development proved to be another important variable. At both schools teacher learning and professional development related to ICT have been supported by the school leadership. However the two schools have nurtured different approaches to ensuring access to quality learning experiences related to the integration of ICT.

According to Kate, at Kookaburra Primary School there is an ICT committee that regularly informs teachers about in-school and out-of-school professional development. Teachers are offered opportunities at staff meetings to attend seminars, workshops, and presentations, which they can choose from. Apart from these formal approaches to professional development, teachers often take the opportunity to share good practices with ICT and mentor each other. According to Kate sometimes a colleague "will come up with what they've done, they'll get a projector ready and we will all go". "Teachers are very good like that here. They are happy to give you time, as long as you can find the time to get together, they are happy to share and teach you" Maria adds.

At Platypus Primary School facilitating student learning with ICT has always been considered important. It is one of the hallmarks of the school. Joanne acknowledges that the school has a vision related the integration of ICT and provides students and staff with resources and opportunities for ongoing learning.

It is really important that it just became very much an integrated tool into all areas of the curriculum here, and that we are providing students with the skills that they need, because it is a vital part of their ongoing learning ... (Joanne)

As part of the School's vision, teacher professional development (PD) is a high priority at Platypus Primary. The school leadership facilitates teacher collaboration in order to promote successful integration of ICT in learning and teaching. They offer teachers opportunities to share ideas and learn from each other in the more intimate and comfortable environment of smaller groups referred to as Professional Learning Teams. Working in smaller teams within the school environment reduces some of the pressure and counter-balances anxiety and information overload. It encourages teachers to learn at their own pace and reach beyond their comfort zone without experiencing significant levels of frustration.

We PD among ourselves... and [the school] put on a PD for us... trying to keep us all moving forward, but it is in within your comfort zone, it's what you feel capable and comfortable with sticking up and running with. So we have the extremes, and a lot of people in the middle, who are very $O K$ with more common programs like Word and PowerPoint and possibly Publisher. But there are those who are committed to looking into some of the other wider possibilities as well. (Gina) 
Platypus Primary takes a holistic approach to ICT integration. It has an ICT manager that strategically works with students and staff to improve teaching and learning with ICT. Apart from providing teachers with just-in-time professional development and technical support, the school draws on mobilising student expertise in order to minimise challenges such as technological glitches and diverse skill levels in using ICT. The importance of drawing on the expertise of students has been widely recognised by this school through organising a special programme for students interested in ICT or having advanced skills in using new technologies. The programme prepares them for peer-teaching and for co-teaching with teachers. Joanne argues that this valuable initiative enables students to share their expertise and develop their leadership skills.
[It] provides an opportunity for students who have a talent in a particular area, to have that talent explored further, and the expert's program enables all children to have an opportunity to develop those leadership roles, and I think if you are encouraging students to take on those leadership roles it is really important to provide the opportunities for them to refine their skills in that area and give them opportunity to use them (Joanne).

Supportive school culture contributes to significant changes in classroom relationships and teaching philosophies thus facilitating pedagogical and cultural shifts. According to Gina, roles and relationships are changing in the classroom as students are often more confident users of ICT than teachers. She sees a potential for professional growth in this: "Students bring a lot more of the expertise in the area of ICT, they are so much more immersed in it, and I think, as a teacher you have potential to grow" (Gina). Although she is a confident user of ICT, at times she is ready to take up the role of the learner and learn from her students:

I often say to the kids: “Well, yeah, you showed me, that's great". And I think if you stay open to the learning, basically they stay open to the learning as well and they feel a sense of achievement and comfort, and leadership too, that they have this knowledge that they can share with you, it's a two-way street, I think the relationship has changed... (Gina)

Joanne believes that education is about learning from each other. The teacher's role in such a learning environment is to scaffold the learning experiences and student collaboration, as well as to question existing interpretations and look for alternatives. Joanne willingly takes up the role of the learner when it comes to new and emerging technologies.

Education, particularly in my classroom, and I think education in general, is a co-learning experience - we learn from each other... Where the children feel confident to develop their leadership skills, where they feel confident to explore new understandings, and question things that are happening, and to offer alternatives to them... From a pedagogical practice idea of co-learners I see myself as learning to use ICT... So quite often I say to my students that I am learning this with you. (Joanne) 


\section{Conclusions}

This paper contributes to current interpretations of barriers and catalysts for effective practices with ICT by reporting on the perceptions of four teachers teaching in two Victorian government primary schools. While the generalisability of findings may be limited by the small number of participants, results of this study provide important leads for schools and policy developers in maximising their efforts to respond to the challenges of ICT integration in contemporary primary schools.

Teacher interviews reveal that when integrating new technologies operational risk management comes before pedagogical innovation. Findings confirm the results of the 2005 Pisa evaluation [6] according to which access to reliable ICT infrastructure appears to be the most significant barrier to effective practices with ICT. The effects of technical problems are further amplified by the lack of just-in-time technical support, which results in increased anxiety and a focus on risk management [26, 27], hence decreasing teachers' creative capacity to transform student learning with ICT.

Time also appears to be an important variable affecting the integration of ICT. Similarly to Cuban et al. [4], teachers participating in this study argue that lack of time to experiment and learn about new technologies hinders their integration of ICT into the learning environment. More importantly time constraints also appear to influence classroom practices, with traditional timetables interfering with new pedagogies and innovative approaches to teaching and learning.

Teachers also report on a number of variables that act as catalysts to effective practices with ICT. These include owning a laptop, having access to professional learning opportunities, sharing effective practices, drawing on student expertise and by being supported by a whole-school approach to technology integration. Findings of this study indicate the having access to their own laptop eliminates the traditional boundaries of time and space and provides teachers with flexible opportunities for experimenting with new technologies. This in turn increases teachers' confidence and competence in integrating ICT in their professional practices. This finding corroborates the results of the teacher survey (which was also part of this research project), indicating that having access to computers at home has a statistically significant influence on all dimensions of teachers' ICT literacy, including teachers' pedagogical understanding in facilitating student learning with new technologies [28].

Finally, findings suggest that the integration of ICT is more effective when supported by a whole-school approach that draws on teacher collaboration and on student expertise. The example of Platypus Primary School demonstrates that ICT integration is more successful when teachers are provided with relevant, 'just-in-time' professional learning [29] in a familiar environment that allows them to move forward with ICT within their comfort zone. These findings support Demetriadis et al.'s [30] and Coppola's [31] observations according to which "teachers learn better in the real setting of their own workplace when they are not isolated culturally and structurally" [31, p. 37]. In such communities of practice [32, 33], teachers are more likely to engage in ongoing learning related to the integration of ICT, which helps them develop their agency to facilitate pedagogical and cultural shifts. 


\section{Acknowledgements}

I would like to express my gratitude to the participants of the teacher interviews, the Australian Postgraduate Award (APA), and my PhD supervisors, Associate Professor Colleen Vale and Professor Brenda Cherednichenko for their support and contribution to this research.

\section{References}

1. Apple, M.W.: Are We Wasting Money on Computers in Schools? Educational Policy 18(3), 513-522 (2004)

2. Yelland, N.: Shift to the Future: Rethinking Learning with New Technologies in Education. Routledge, New York (2007)

3. Bauer, J., Kenton, J.: Toward Technology Integration in the Schools: Why It Isn't Happening. Journal of Technology and Teacher Education 14(4), 519-541 (2005)

4. Cuban, L., Kirkpatrick, H., Peck, C.: High Access and Low Use of Technologies in High School Classrooms: Explaining an Apparent Paradox. American Educational Research Journal 38(4), 813-834 (2001)

5. Jones, A.: A Review of the Research Literature on Barriers to the Uptake of ICT by Teachers. British Educational Communications and Technology Agency (Becta), Coventry (2004)

6. OECD: Are Students Ready for a Technology Rich World?: What PISA Studies Tell Us? (2006), http: / /www. oecd.org/dataoecd/28/4/35995145.pdf

7. Pierson, M.E.: Technology Integration Practice as a Function of Pedagogical Expertise. Journal of Research on Computing in Education 4(33), 413-430 (2001)

8. Warschauer, M.: Demystifying the Digital Divide. Scientific American 289(2), 42-47 (2003)

9. Dakich, E.: Towards the Social Practice of Digital Pedagogies. In: Yelland, N., Neal, G., Dakich, E. (eds.) Rethinking Education with ICT: New Directions for Effective Practices, pp. 13-30. Sense Publishers, Rotterdam (2008)

10. Warschauer, M.: Literacy and Technology: Bridging the Divide. In: Gibbs, D., Krause, K.L. (eds.) Cyberlines 2: Languages and Cultures of the Internet, James Nicholas, Albert Park, Australia, pp. 163-176 (2006)

11. Warschauer, M., Knobel, M., Stone, L.: Technology and Equity in Schooling: Deconstructing the Digital Divide. Educational Policy 18(4), 562-588 (2004)

12. Wood, E., Mueller, J., Willoughby, T., Specht, J., Deyoung, T.: Teachers' Perceptions: Barriers and Supports to Using Technology in the Classroom. Education, Communication and Information 5(2), 183-206 (2005)

13. Rubin, H.J., Rubin, I.S.: Qualitative Interviewing: The art of hearing data, 2nd edn. Sage Publications, Thousand Oaks (2005)

14. Dakich, E.: Mediating the Frames of Meaning through Mixed-Methods Research. Conference Presentation, Mixed Methods Conference 2006, Cambridge, UK (2006)

15. Babbie, E.: The Practice of Social Research, 10th edn. Thomson Wadsworth, Belmont (2004)

16. Creswell, J.W.: Educational Research: Planning, conducting, and Evaluating Quantitative and Qualitative Research, 2nd edn. Pearson Education, Upper Saddle River (2005) 
17. Cherednichenko, B., Davies, A., Kruger, T., \& O'Rourke, M.: Collaborative Practices: From Description to Theory. Paper Presented at the AARE 2001 Conference (2001), http: / /www. aare.edu.au/01pap/dav01436.htm

18. Miles, M.B., Huberman, A.M.: Qualitative Data Analysis, 2nd edn. Sage Publications, Thousand Oaks (1994)

19. Silverman, D.: Doing Qualitative Research. Sage Publications, London (2005)

20. Guba, E.G., Lincoln, Y.S.: Effective Evaluation: Improving the Usefulness of Evaluation Results through Responsive and Naturalistic Approaches. Jossey-Bass Publisher, San Francisco (1981)

21. Lincoln, Y.S., Guba, E.G.: Naturalistic Inquiry. Sage Publications, Newbury Park (1985)

22. Creswell, J.W., Miller, D.L.: Determining Validity in Qualitative Inquiry. Theory Into Practice 39(3), 124-130 (2000)

23. Bowden, J.A., Walsh, E.: Phenomenography. RMIT University Press, Melbourne (2000)

24. Harris, L.R.: A Phenomenographic Investigation of Teacher Conceptions of Student Engagement in Learning. The Australian Educational Researcher 35(1), 57-79 (2008)

25. DE\&T: Notebooks for Teachers and Principals Programme (1998), http://www.education.vic.gov.au/management/ ictsupportservices/notebooks / default.htm

26. Becta: What the Research Says about Barriers to the Use of ICT in Teaching (2003), http: / / partners.becta.org.uk/upload-dir/downloads / page_documents/research/wtrs_barriersinteach.pdf

27. Webb, J., Schirato, T.: Communication Technology and Cultural Politics. Convergence: The International Journal of Research into New Media Technologies 12(3), 255-261 (2006)

28. Dakich, E., Vale, C., Thalathoti, V., Cherednichenko, B.: Factors Influencing Teachers' ICT Literacy: A Snapshot from Australia. In: Luca, J., Weippl, E.R. (eds.) Ed-Media 2008: World Conference on Educational Multimedia, Hypermedia and Telecommunications, pp. 3672-3680. AACE, Chesapeake (2008)

29. Lloyd, M., Cochrane, J., Beames, S.: Dynamic Not Static: Characteristics of Effective Teacher Professional Development in ICT. Paper Presented at the AARE Conference, 2005 (2005), http: / /www . aare. edu. au/05pap/11005773.pdf

30. Demetriadis, S., Barbas, A., Molohides, A., Palaigeorgiou, G., Psillos, D., Vlahavas, I., et al.: "Cultures in negotiation": Teachers' Acceptance/Resistance Attitudes Considering the Infusion of Technology into Schools. Computers and Education 41(1), 19-37 (2003)

31. Coppola, E.M.: Powering up: Learning to Teach Well with Technology. Teachers College Press, New York (2004)

32. Krumsvik, R.: ICT and Community of Practice. Scandinavian Journal of Educational Research 49(1), 27-50 (2005)

33. Wenger, E., McDermott, R.A., Snyder, W.: Cultivating Communities of Practice: A Guide to Managing Knowledge. Harvard Business School Press, Boston (2002) 